\title{
Wireless Communication Problem Identified
}

National Cancer Institute

\section{Source}

National Cancer Institute. Wireless Communication Problem Identified. NCI Thesaurus.

Code C92132.

Communications problems between devices within a wireless system. 